\title{
Article \\ Biosynthesis Microwave-Assisted of Zinc Oxide Nanoparticles with Ziziphus jujuba Leaves Extract: Characterization and Photocatalytic Application
}

\author{
Maymounah N. Alharthi ${ }^{1,2}$, Iqbal Ismail ${ }^{1}$, Stefano Bellucci ${ }^{3}\left(\mathbb{D}\right.$, Nezar H. Khdary ${ }^{4}$ \\ and Mohamed Abdel Salam 1,*(D) \\ 1 Department of Chemistry, Faculty of Science, King Abdulaziz University, P.O. Box 80200, \\ Jeddah 21589, Saudi Arabia; chem-28@hotmail.com (M.N.A.); iismail@kau.edu.sa (I.I.) \\ 2 Department of Chemistry, College of Science, Princess Nourah bint Abdulrahman University, \\ P.O. Box 84428, Riyadh 11671, Saudi Arabia \\ 3 National Laboratories of Frascati, National Institute of Nuclear Physics, I-00044 Frascati, Italy; \\ stefano.bellucci@lnf.infn.it \\ 4 King Abdulaziz City for Science and Technology, P.O. Box 6086, Riyadh 11442, Saudi Arabia; \\ nkhdary@kacst.edu.sa \\ * Correspondence: masalam16@hotmail.com; Tel.: +966-541886660; Fax: +966-2-6952292
}

\section{check for}

updates

Citation: Alharthi, M.N.; Ismail, I.; Bellucci, S.; Khdary, N.H.; Abdel Salam, M. Biosynthesis

Microwave-Assisted of Zinc Oxide Nanoparticles with Ziziphus jujuba Leaves Extract: Characterization and Photocatalytic Application. Nanomaterials 2021, 11, 1682. https:// doi.org/10.3390/nano11071682

\section{Academic Editors: Alexandru}

Mihai Grumezescu, Oana Gherasim and José Antonio Navío

Received: 1 June 2021

Accepted: 24 June 2021

Published: 26 June 2021

Publisher's Note: MDPI stays neutral with regard to jurisdictional claims in published maps and institutional affiliations.

Copyright: (c) 2021 by the authors. Licensee MDPI, Basel, Switzerland. This article is an open access article distributed under the terms and conditions of the Creative Commons Attribution (CC BY) license (https:// creativecommons.org/licenses/by/ $4.0 /)$.
Abstract: The present work is intended to biosynthesize zinc oxide nanoparticles (ZnO NPs) via facile and modern route using aqueous Ziziphus jujuba leaves extract assisted by microwave and explore their photocatalytic degradation of methyl orange anionic dye and methylene blue cationic dye under solar irradiation. The biosynthesized microwave assisted ZnO NPs were characterized and the results showed that ZnO NPs contain hexagonal wurtzite and characterized with a well-defined spherical-like shape with an outstanding band gap $(2.70 \mathrm{eV})$, average particle size of $25 \mathrm{~nm}$ and specific surface area of $11.4 \mathrm{~m}^{2} / \mathrm{g}$. The photocatalytic degradation of the $\mathrm{MO}$ and $\mathrm{MB}$ dyes by biosynthesized $\mathrm{ZnO}$ NPs under solar irradiation was studied and the results revealed the selective nature of the $\mathrm{ZnO}$ NPs for the adsorption and further photocatalytic degradation of the MO dye compared to the MB dye. In addition, the photocatalytic degradation of MO and MB dyes by the $\mathrm{ZnO}$ NPs under solar radiation was fitted by the first-order kinetics. Moreover, the photodegradation mechanism proposed that superoxide ions and hydroxyl radicals are the main reactive species.

Keywords: Azo dye; photocatalytic degradation; solar irradiation; ZnO NPs

\section{Introduction}

Currently, nanotechnology is based on the preparation, characterization and applications of different nanoparticles (NPs) such as metals, metal oxides, semiconductors, ceramics and polymers, due to their outstanding morphological, structural and physicochemical properties allowed the NPs to be the used in a wide variety of applications. Among the most commonly used nanoparticles is zinc oxide nanoparticles (ZnO NPs), which are usually used in different applications, such as corrosion protection [1], food packaging [2], biomedical [3-5], electronics [6], revolutionizing agriculture [7], textiles [8] and as photocatalysts for environmental applications [9-13]. The synthesis of ZnO NPs are usually based on various physical, and chemical process, such as via combustion, thermal decomposition, sol-gel method, mechanical synthesis combined with high-energy milling and hydrothermal methods, which are mainly based on the usage of different chemicals and reagents such as the aqueous solution of zinc nitrate, zinc sulphate or zinc acetate as the precursor, followed by provision of basic environment such as sodium hydroxide or ammonia, in addition to some additives acting similarly to capping agents to produce well defined nanoparticles such as polyethylenimine (PEI) or polyethylene glycol (PEG) [14-16]. The physical and chemical processes for synthesis of ZnO NPs 
usually generate chemical waste, leading to adverse effects on the life of flora and fauna and, critically, water. Recently, an alternative and interesting trend was adopted to minimize the generation of such chemical waste known as biosynthesis, or green synthesis, of nanoparticles, where various plant parts extract have been used for this synthesis, as the biosynthesis of $\mathrm{ZnO}$ NPs in comparison with conventional synthesis is recommended, as it has minimal impact on the environment and is without health risk [17]. In several studies, the extract of various plants parts have been applied for the biosynthesis of $\mathrm{ZnO}$ NPs, such as Azadirachta indica (Neem) leaf [18], Abelmoschus esculentus (okra) mucilage [19], Cuminum cyminum (cumin) [20], Mangifera indica (mango) leaves [21], Calotropis gigantea leaves [22], Aloe socotrina leaf [23], Parkia roxburghii seeds [24], Nigella sativa seed [25] and Ziziphus jujube (Sidr or Nabq) [26], where the plant extracts act as capping and stabilizing agents [17], which stabilized the formed nanoparticles, and prevent the agglomeration of the particles. In addition, the biosynthesized ZnO NPs were characterized with comparable, and most of the times higher activities when compared with traditionally prepared nanoparticles [17-27]. Ziziphus jujube is a very common plant that is grown locally in Saudi Arabia and surrounding areas and is used extensively for its health properties [28-31]. It was found that the medicinal benefits of Ziziphus jujube are anti-inflammatory effects, antimicrobial, antioxidant and anticancer [28-31]. The Ziziphus jujube plant is rich in several organic compounds, including phenolic compounds, beta-carotene, alpha-tocopherol, alkaloids, sterols, flavonoids, saponin, tannins and fatty acids which could act as capping agent, and prevent the agglomeration of the NPs due to the existence of long chain natural products in the plant extract [32,33].

Moreover; the preparation of metal oxide NPs such as $\mathrm{ZnO}$ using microwave was the focus of many research, mainly due to the superior heating rate when compared to traditional heating methods as a result of volumetric heating, in addition to the fact that microwaves usually provide high energy by penetrating the material, allowing the reaction to be completed in minutes or even seconds, in addition to the possibility to control the $\mathrm{ZnO}$ NPs properties; such as purity, low cost, reproducibility of the produced NPs and fulfilment of the eco-friendly approach criterion as well. [34-39].

The hypothesis of the current work in the use of Ziziphus jujube leaves extract assisted with microwave could produce ZnO NPs characterized with outstanding colloidal stability, more uniform size, shape and higher reactivity compared to the traditionally prepared $\mathrm{ZnO}$ NPs.

Accordingly, the objective of the current research is the biosynthesis of ZnO NPs using aqueous extract of Ziziphus jujube leaves assisted with microwave heating. The biosynthesized ZnO NPs were characterized using different characterization techniques to explore their morphological, physical and chemical properties, then used for the photocatalytically degradation of two different organic dyes: methyl orange anionic dye and the methylene blue cationic dye, under solar irradiation.

\section{Materials and Methods}

\subsection{Materials}

All chemicals (analytical grade) were purchased from Sigma-Aldrich Canada (Oakville, ON, Canada), and the solutions were prepared with deionized water.

\subsection{Methods}

\subsubsection{Ziziphus jujuba Leaves Extract (Sidr) Preparation}

Fresh and healthy leaves of Ziziphus jujuba (Sidr) were collected from Jeddah, Saudi Arabia, on October 2019. The leaves were washed very well with tap water, then with deionized water and were dried on air at ambient temperature, then the cleaned leaves were chopped and grounded and $5.0 \mathrm{~g}$ was added to a $100 \mathrm{~mL}$ of deionized water in a beaker. The mixture was boiled for $20.0 \mathrm{~min}$, then cooled to room temperature and was centrifuged at 3,600 rpm for $30 \mathrm{~min}$, till a clear filtrate was obtained and stored at $4{ }^{\circ} \mathrm{C}$. 


\subsubsection{Traditional ZnO NPs (T ZnO NPs) Preparation}

An aqueous solution of zinc acetate $(250 \mathrm{~mL}, 0.2 \mathrm{M})$ and the solution of $\mathrm{NaOH}(250 \mathrm{~mL}$, $0.5 \mathrm{M}$ ) were prepared with deionized water. The $\mathrm{NaOH}$ solution was added drop by drop using a burette to the zinc acetate solution at room temperature under vigorous stirring, which resulted in the formation of the white precipitate of zinc hydroxide. The white precipitate of the zinc hydroxide was separated by centrifugation at $3900 \mathrm{rpm}$ for $30 \mathrm{~min}$ and washed three times with distilled water, followed by ethanol. The obtained product was dried at $60^{\circ} \mathrm{C}$ in air atmosphere for $24 \mathrm{~h}$ to convert the $\mathrm{Zn}(\mathrm{OH})_{2}$ to $\mathrm{ZnO}$ NPs.

\subsubsection{Biosynthesis of $\mathrm{ZnO}$ NPs (B ZnO NPs)}

An aqueous solution of Zinc acetate $(250 \mathrm{~mL}, 0.2 \mathrm{M})$ and the solution $(250 \mathrm{~mL}, 0.5 \mathrm{M})$ of $\mathrm{NaOH}$ were prepared using the Ziziphus jujuba leaves extract $(5 \mathrm{~mL})$. The $\mathrm{NaOH}$ solution was added drop by drop using a burette to the zinc acetate solution; prepared with the extract, at room temperature under vigorous stirring, which resulted in the formation of the light-brown precipitate of zinc hydroxide. The light-brown precipitate was separated by centrifugation at $3900 \mathrm{rpm}$ for $30 \mathrm{~min}$ and washed three times with distilled water, followed by ethanol. The obtained product was dried at $60^{\circ} \mathrm{C}$ in air atmosphere for $24 \mathrm{~h}$ to convert the $\mathrm{Zn}(\mathrm{OH})_{2}$ to $\mathrm{ZnO}$ NPs.

\subsubsection{Biosynthesis Microwave-Assisted ZnO NPs (BMW ZnO NPs)}

Aqueous solution of zinc acetate $(250 \mathrm{~mL}, 0.2 \mathrm{M})$ and the solution $(250 \mathrm{~mL}, 0.5 \mathrm{M})$ of $\mathrm{NaOH}$ were prepared using the Ziziphus jujuba leaves extract $(5 \mathrm{~mL})$. The $\mathrm{NaOH}$ solution was added drop by drop using a burette to the zinc acetate solution; prepared with the extract, at room temperature under vigorous stirring at $1000 \mathrm{rpm}$ using Stuart ${ }^{\mathrm{TM}}$ hotplate stirrer model CB162, which resulted in the formation of the light-brown precipitate of zinc hydroxide. The resultant solution was treated by using $800 \mathrm{~W}$ household digital microwave oven (Nikai, NMO-518N, Japan) for 5 min to convert the $\mathrm{Zn}(\mathrm{OH})_{2}$ to $\mathrm{ZnO}$ NPs, then the precipitate was separated by centrifugation using Sigma Centrifuge (model 2-7) at $3900 \mathrm{rpm}$ for $30 \mathrm{~min}$ and washed three times with distilled water, followed by ethanol. The obtained product was dried at $60^{\circ} \mathrm{C}$ in air atmosphere for $24 \mathrm{~h}$.

\subsection{Characterization Methods}

The FT-IR spectra for the FT-IR spectra of Ziziphus jujuba leaves extract, and different ZnO NPs, were recorded using FTIR spectrophotometer (Shelton, CT, USA). X-ray diffraction (XRD) patterns were recorded for phase analysis and the measurement of crystallite size was performed on a Philips X-pert pro diffractometer (Malvern, Worcestershire, United Kingdom). The instrument was operated at $40 \mathrm{~mA}$ and at $40 \mathrm{kV}$ on a $\mathrm{CuK} \alpha$ radiation and a nickel filter in the $2 \theta$ range from 2 to $80^{\circ}$ in steps of $0.02^{\circ}$, with a sampling time of one second per step. Estimation of the crystal size was achieved according to the Scherrer equation [40]. The morphological structures of the prepared $\mathrm{ZnO}$ NPs were studied using JEOL JEM-1011 high-resolution transmission electron microscope (TEM) (Peabody, MA, USA) that operated $80 \mathrm{kV}$. The specific surface area of the $\mathrm{ZnO}$ NPs were estimated using the nitrogen adsorption/desorption isotherm at $77 \mathrm{~K}$, by NOVA3200e (Quantachrome, Boynton Beach, FL, USA), and prior to measurements, the samples were outgassed under vacuum (5 millitorrs) at were degassed at $473 \mathrm{~K}$; the outgas rate was $5 \mathrm{mmHg} / \mathrm{min}$ till the sample was degassed. The absorbance and the band gap estimation were measured using a UV-3600 from Shimadzu (Nakagyo-ku, Kyoto, Japan). For absorbance measurement, $20 \mathrm{mg}$ of the sample was mixed with $100 \mathrm{mg}$ of $\mathrm{KBr}$ and then ground very well to prepare a transparent pellet. After that, the pellet was used for the measurement of absorbance.

\subsection{Photocatalytic Experiments}

The application of $\mathrm{ZnO}$ NPs as a photocatalyst for environmental remediation via photocatalytic degradation was performed using a mixture of the two azo dyes solutionmethyl orange (MO) and methylene blue (MB), under direct sunlight. A $20 \mathrm{~mL}$ mixture 
of 5 ppm of MO and 5 ppm MB dyes were used, and $15 \mathrm{mg}$ of $\mathrm{ZnO}$ NPs were added and stirred for $30 \mathrm{~min}$ in the dark, then the solution was exposed to direct sunlight between 10 am to $12 \mathrm{pm}$, and the light flux was $700 \pm 20 \mathrm{~W} / \mathrm{m}^{2}$ during the whole period. An aliquot of the mixture was withdrawn at designated time intervals, the ZnO NPs were separated by centrifuge and then the concentration of the remaining $\mathrm{MO}$ and MB dyes in each solution was determined by ultraviolet-visible spectrophotometer (UV-1650 PC, CPS-240A, SHIMADZU, Nakagyo-ku, Kyoto, Japan) at 464 nmand 664 nm, respectively. The removal efficiency was estimated by applying the following equation:

$$
\% \text { Removal }=\frac{100 \times\left(C_{0}-C_{t}\right)}{C_{0}}
$$

where $C_{0}$ is the initial concentration and $C_{t}$ : the residual concentration in solution at a certain time $(t)$.

\section{Results and Discussion}

\subsection{Characterization of $\mathrm{ZnO} N \mathrm{NS}$}

Figure 1 present the FT-IR spectra of Ziziphus jujuba leaves extract, as well as the different synthesized ZnO NPs. The spectrum of Ziziphus jujuba leaves extract (Figure 1A, showed strong absorption peak at $3421 \mathrm{~cm}^{-1}$ was resulted from stretching of the $\mathrm{O}-\mathrm{H}$ groups due to the presence of alcohols, phenols, carbohydrates and etc. [41]. While the peak 2925 and $1637 \mathrm{~cm}^{-1}$ may be attributed to the stretching vibration of $v(=\mathrm{C}-\mathrm{H})$ and $v(C=C)$, and the peak at $1637 \mathrm{~cm}^{-1}$ could also be related to the surface adsorbed water molecule. The peak at $619 \mathrm{~cm}^{-1}$ may be assigned to $\delta(\mathrm{C}-\mathrm{H})$ bending vibration or $\mathrm{C}-\mathrm{S}$, $\mathrm{R}-\mathrm{C}-\mathrm{CH}_{3}$ stretching for Sulphur compounds. Similarly, the bands at 3421 and $1384 \mathrm{~cm}^{-1}$ may be assigned to the stretching vibration of $v(\mathrm{O}-\mathrm{H})$ and in-plane bending vibration of $\delta(\mathrm{O}-\mathrm{H})$, respectively. Moreover, the band at $1052 \mathrm{~cm}^{-1}$ may be contributed by skeletal $\mathrm{C}-\mathrm{O}$ and $\mathrm{C}-\mathrm{C}$ vibration bands of glycosidic and pyrenoid ring [42]. Meanwhile, the FT-IR spectra of different ZnO NPs were analyzed to confirm the phase transformation and purity of the $\mathrm{ZnO}$ (Figure 1B-D). All the FT-IR spectra showed a wide band at $3400 \mathrm{~cm}^{-1}$ thereby indicating the presence of surface hydroxyl groups due to presence of trace amount of water in the ZnO samples. Weak absorption bands centered at about 1640, 1480 and 1370 which can be assigned to asymmetric and symmetric $\mathrm{C}=\mathrm{O}$ stretching modes, respectively, due to traces of the Ziziphus jujuba leaves extract, especially with the biosynthesized ZnO Nps. The peaks appeared in the region between 600 and $450 \mathrm{~cm}^{-1}$ are allotted to metal oxygen vibration ( $\mathrm{Zn}-\mathrm{O})$ of $\mathrm{ZnO}$ nanoparticles [43].

Figure 2 illustrates the XRD patterns of different prepared $\mathrm{ZnO} N P s ; \mathrm{T} \mathrm{ZnO} \mathrm{NPs,}$ B ZnO NPs and BMW ZnO NPs show characteristic peaks at $2 \theta$ angles equals $31.74^{\circ}$, $34.40^{\circ}$ and $36.22^{\circ}$ corresponding to (100), (002) and (101) planes, respectively, relative to hexagonal wurtzite structure (JCPDS file no. 36-1451). The ZnO NPs calculated crystallite size applying the Scherer equation were $21.5 \mathrm{~nm}, 25.7 \mathrm{~nm}, 26.40 \mathrm{~nm}$, for T ZnO NPs, B $\mathrm{ZnO}$ NPs and BMW ZnO NPs, respectively, indicating the increase in the crystallite size due to the thermal treatment via the microwave heating, which was characterized with the rapid, and high temperature compared with the traditional method. The increase in crystallite size with the microwave prepared ZnO NPs could be attributed to thermally promoted crystallite growth [44]. Figure 3 presents the SEM images of the different $\mathrm{ZnO}$ nanoparticles at different magnification power. The SEM images revealed the formation of irregular agglomerated nanoparticles when the ZnO NPs prepared traditionally ( $\mathrm{T} \mathrm{ZnO}$ NPs) or biosynthesized using the the Ziziphus jujuba leaves extract only (B ZnO NPs), as well as the prepared by the microwave assisted using the Ziziphus jujuba leaves extract (BMW ZnO NPs) characterized with uniform and less agglomeration nanoparticles, and accordingly, the ZnO NPs were characterized with TEM to confirm the shape and size of the nanoparticles. Transmission electron microscope images of the ZnO NPs; T ZnO NPs, B ZnO NPs and BMW ZnO NPs are presented in Figure 4, which shows that ZnO NPs exists in several sizes and shapes depending on the preparation method. For example, $\mathrm{T}$ 
ZnO NPs composed of irregular agglomerated particles, and the B ZnO NPs characterized with the irregular flake-shape composed of very small particles with an average particle size of $20 \mathrm{~nm}$, whereas BMW ZnO NPs characterized with the well-defined spherical-like shape with an average particle size of $25 \mathrm{~nm}$. The small size of the B ZnO NPs may be attributed to the presence of the Ziziphus jujuba leaves extract which act as capping agent and prevent the agglomeration of the ZnO NPs due to the existence of long chain natural products such as the polyphenols in the extract [41,42,45-48]. In addition, the well-defined spherical shape of the BMW ZnO NPs compared with the traditional and biosynthesized $\mathrm{ZnO} N P s$ may be ascribed to the thermally promoted crystallite growth due to the fusion of the small particles as a result of the high temperature, as well as the effect of the long chain natural products associated with the Ziziphus jujuba leaves extract.

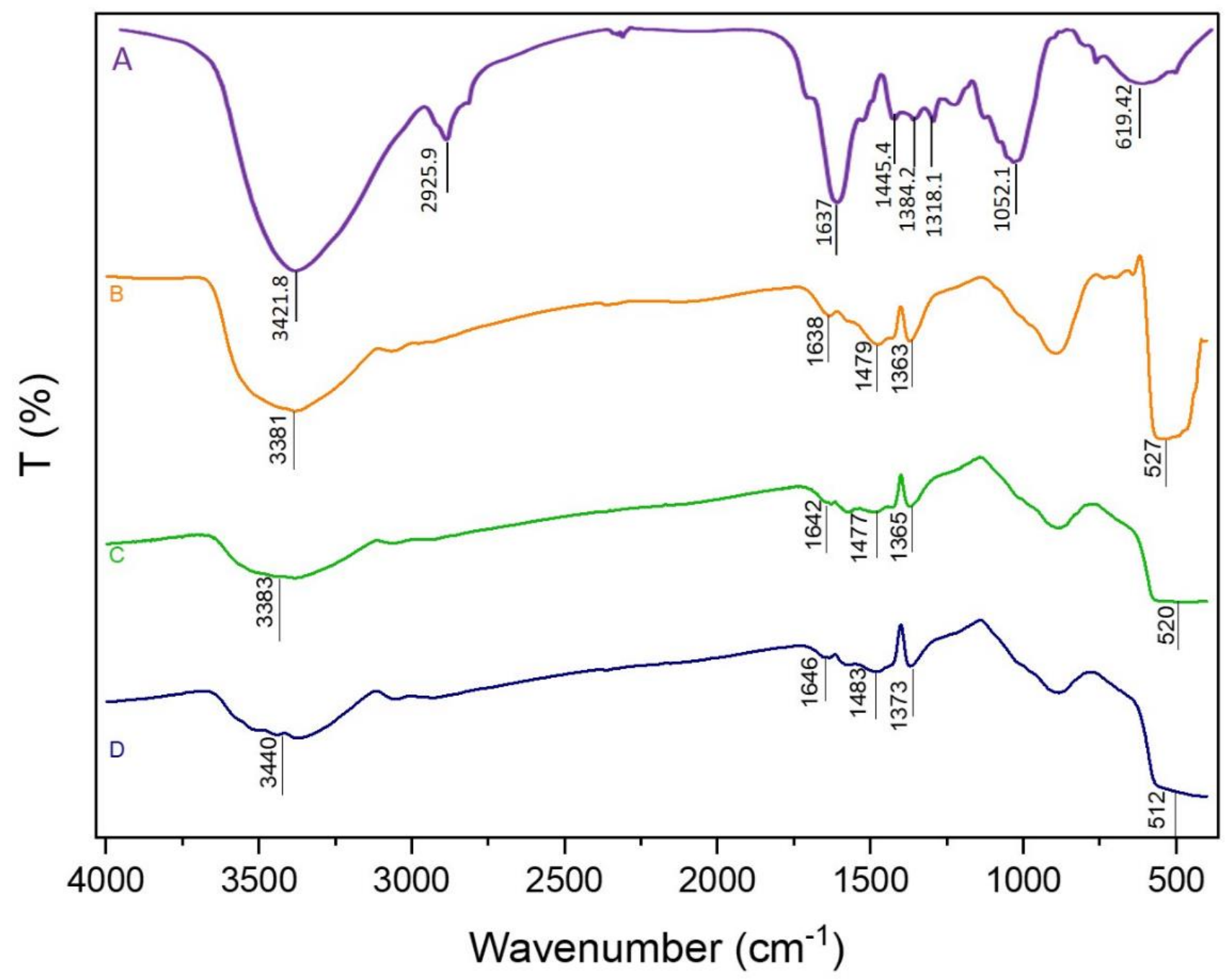

Figure 1. FT-IR spectra of Ziziphus jujuba leaves extract (A), T ZnO NPs (B), B ZnO NPs (C) and BMW ZnO NPs (D). 


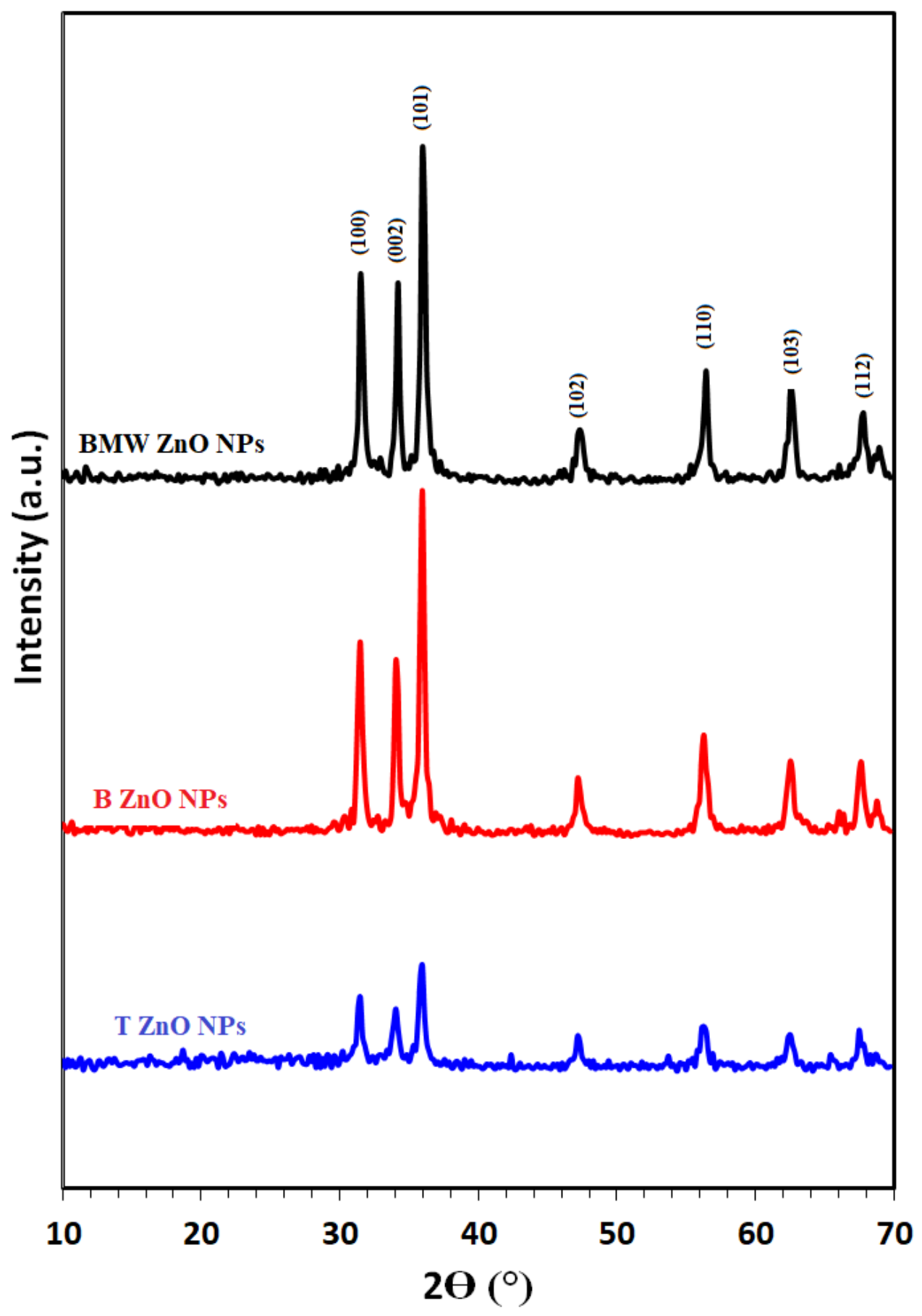

Figure 2. XRD patterns of different ZnO NPs. 


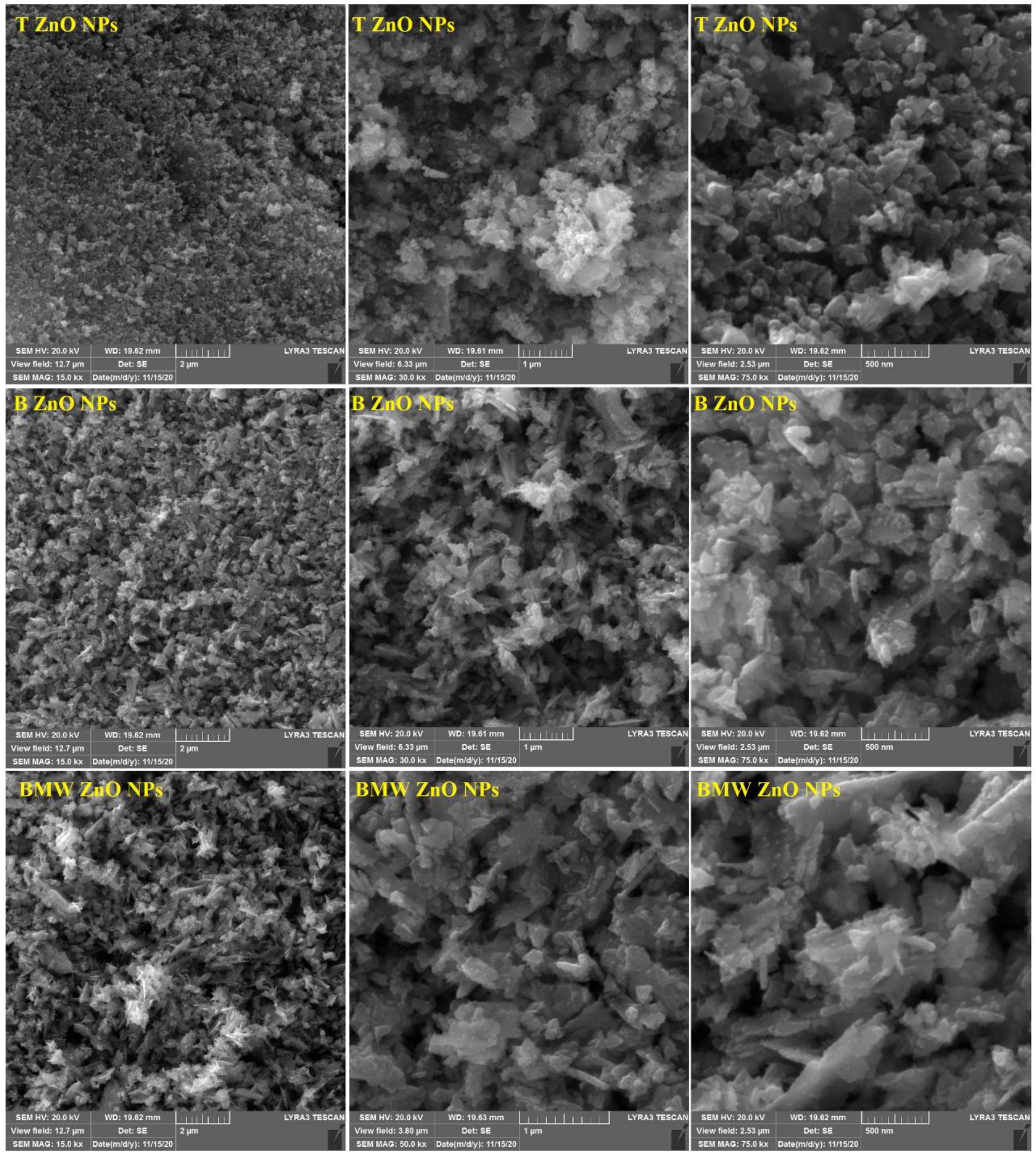

Figure 3. SEM micrographs of different ZnO NPs. 


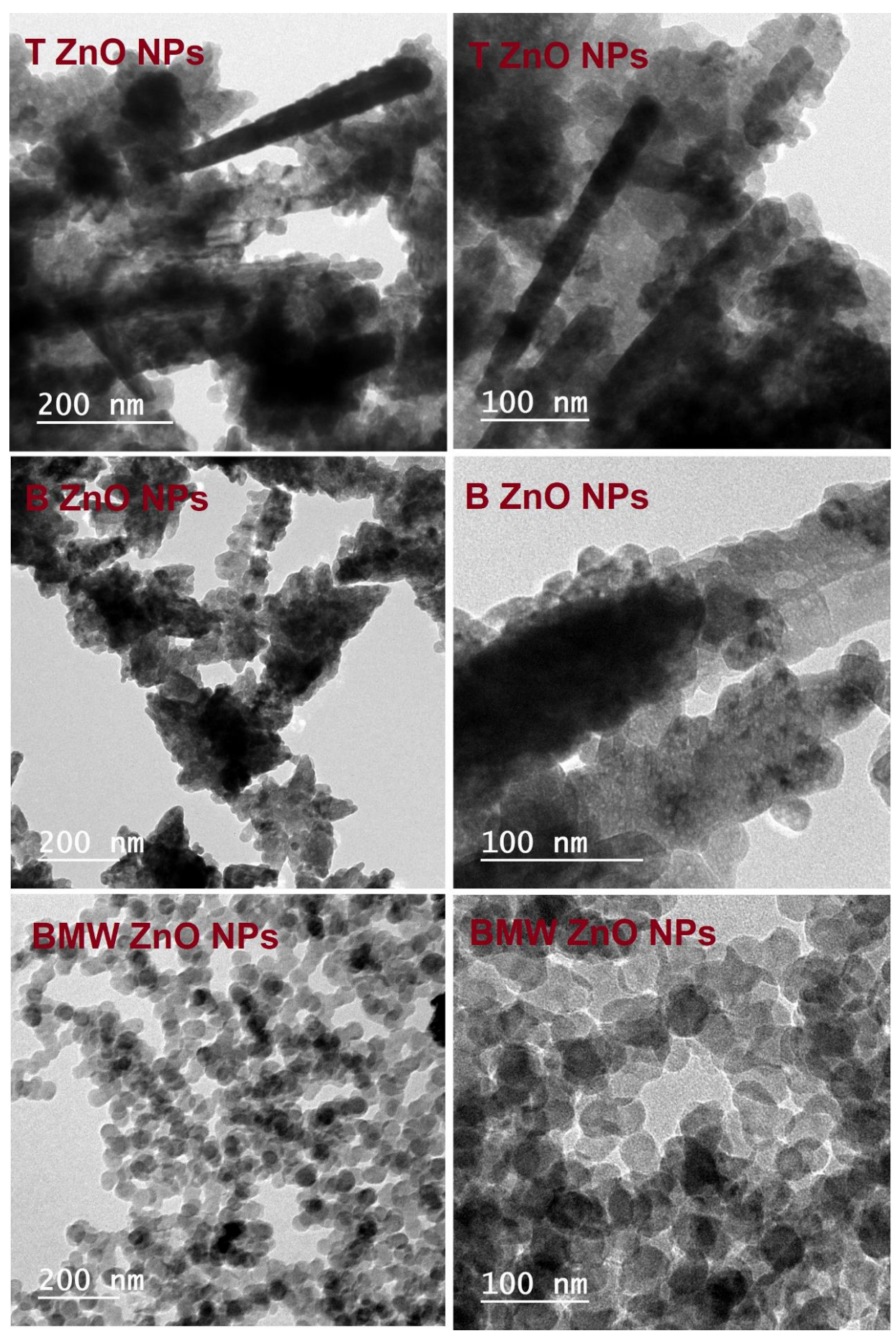

Figure 4. TEM micrographs of different ZnO NPs.

The specific surface areas of the ZnO NPs were calculated from the nitrogen gas adsorption/desorption isotherms at $77 \mathrm{~K}$ applying the BET equation, as shown in Figure 5. The BET specific surface areas were $12.7,11.5$ and $11.4 \mathrm{~m}^{2} / \mathrm{g}$ for the $\mathrm{T} \mathrm{ZnO} \mathrm{NPs,} \mathrm{B} \mathrm{ZnO}$ NPs and BMW ZnO NPs, respectively, indicating a slight decrease in the surface area upon the microwave treatment. The average particles size (D) of BMW ZnO NPs was estimated based on their spherical shape, calculated specific surface area and the ZnO NPs theoretical density using the following equation $[49,50]$ :

$$
\mathrm{D}=(\mathrm{N} \times 1000) /(\mathrm{SSA} \times \rho)
$$


where $\mathrm{D}$ is average particle size of particles $(\mathrm{nm}), \mathrm{N}$ is the shape coefficient $(\mathrm{N}=6$ for the spherical shape), SSA is specific surface area $\mathrm{m}^{2} / \mathrm{g}$ and $\rho$ is theoretical density of the $\mathrm{ZnO}$ NPs $\left(5.61 \mathrm{~g} / \mathrm{cm}^{3}\right)$. The calculated average particle size was $98.8 \mathrm{~nm}$, based on the SSA value of $11.4 \mathrm{~m}^{2} / \mathrm{g}$ of the BMW ZnO NPs, which is significantly higher than the TEM value of $25 \mathrm{~nm}$ and the crystallite size of crystallite size of $26.40 \mathrm{~nm}$ estimated by applying the Scherer equation to the main diffraction peak at $2 \theta$ value of $36.22^{\circ}$ corresponding to (101) plane.
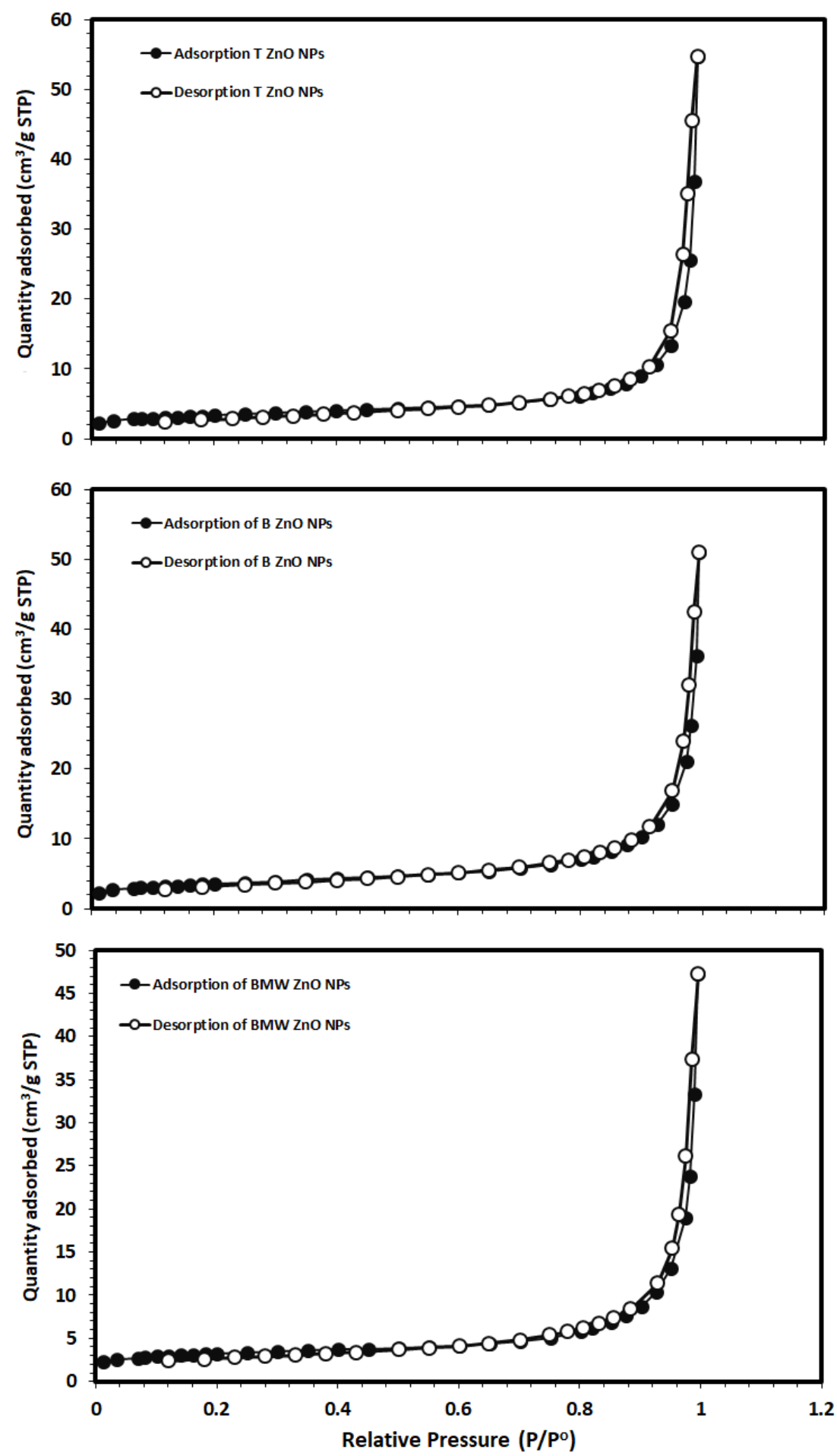

Figure 5. $\mathrm{N}_{2}$ adsorption/desorption isotherms of different $\mathrm{ZnO}$ NPs. 
In order to investigate the optical property of the traditional and biosynthesized ZnONPs on the band gap energy value, the UV-Vis absorbance spectra were recorded at room temperature in the range of $200-800 \mathrm{~nm}$ and are shown in Figure 6. As can be seen from figure, the position of the absorption spectra exhibits red shift with the biosynthesis which indicates that the band gap of $\mathrm{ZnO}$ material decreases compared with traditional method. It shows the UV-vis absorption spectra of $\mathrm{ZnO}$ nanoparticles exhibiting absorption peak at $364 \mathrm{~nm}, 368$ and $370 \mathrm{~nm}$ for T ZnO NPs, B ZnO and, BMW, respectively.
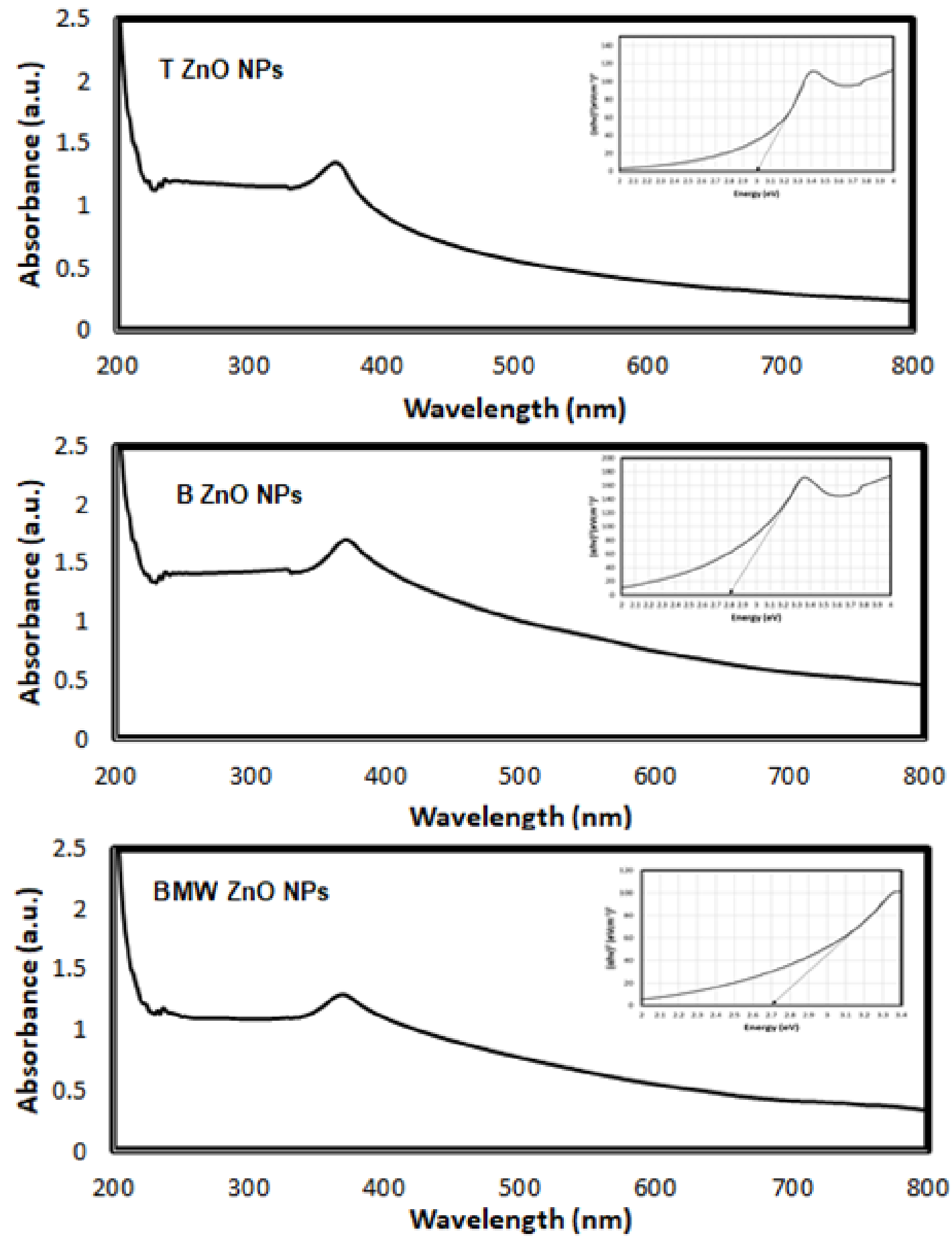

Figure 6. Evaluation of band-gap energy for $\mathrm{ZnO}$ photocatalysts. 
The optical band gap energy $(\mathrm{Eg})$ of the samples is determined by fitting the absorption data using Tauc's relation [51]:

$$
\alpha h v=\mathrm{E}(\mathrm{h} v-\mathrm{Eg}) 1 / 2
$$

where $\mathrm{h} v$ is the photon energy, Eg is the direct band gap and E is a constant, $\alpha$ is the optical absorption coefficient and found from the absorption data. As presented in Figure 6, plotting $(\alpha h v) 2$ as a function of photon energy (hv) and extrapolating the linear portion of the curve to zero absorption gives the value of the direct band gap (Eg). It was observed that the band-gap energy was decreased to 2.70, 2.80 and $3.00 \mathrm{eV}$ for BMW ZnO NPs, B ZnO NPs and T ZnO NPs, respectively, which were lower than the typical ZnO (3.2 eV) [52]. Compared to the bulk $\mathrm{ZnO}$, the optical band gap of the prepared $\mathrm{ZnO}$ NPs were smaller, which may be due to the structural defects that arising during the sample synthesis. As it is well known, the point effects in $\mathrm{ZnO}$ introduce levels within the bandgap lead to the appearance of the wide deep level emission band covering the whole visible range [53]. The wide band gap of $\mathrm{ZnO}$ indicates that it is difficult to photo-excite electrons from the valance band $(\mathrm{VB})$ to the conduction band $(\mathrm{CB})$ under visible light. However, the presence of 4 oxygen vacancies in $\mathrm{ZnO}$ as surface defects plays an important role in optical absorption in visible light region. Theoretical calculations by first principle density functional theory (DFT) concluded that the valence states near Fermi level originated from the O2p and Zn3d states in the valence band can lead to the electronic transitions in visible region $[54,55]$.

\subsection{Photocatalytic Degradation of $M O$ and $M B$}

The photocatalytic degradation of $\mathrm{MO}$ and $\mathrm{MB}$ was explored using $\mathrm{T} \mathrm{ZnO}$ NPs, B ZnO NPs and the BMW ZnO NPs under the solar irradiation, and the results revealed that the most of the MO and MB dyes were removed within 100 min using BMW ZnO NPs, 100.0\% and $99.6 \%$, respectively, whereas in the case of B ZnO NPs it required $150 \mathrm{~min}$ to remove most of the dyes-95.5\% and $96.6 \%$ removal for $\mathrm{MO}$ and $\mathrm{MB}$ dyes, respectively, meanwhile in the case of $\mathrm{T}$ ZnO NPs it required $180 \mathrm{~min}$ to remove most of the dyes-94.2\% and $92.6 \%$ removal for $\mathrm{MO}$ and $\mathrm{MB}$ dyes, respectively. The high photodegradation efficacy of the BMW ZnO NPs may be attributed to the small band gap (2.70 eV), compared with the B ZnO NPs $(2.80 \mathrm{eV})$ and $\mathrm{T}$ ZnO NPs $(3.00 \mathrm{eV})$, which facilitate the photocatalytic degradation of the organic dyes, as a results of the uniform spherical shape of the biosynthesized microwave treatment of the ZnO NPs, as the geometrical shape play an important role in the reactivity of the nanoparticles $[17,56]$, which presents the unique characteristics of the biosynthesized microwave-assisted ZnO NPs. Accordingly, further photocatalytic degradation experiments were performed using the MWG ZnO NPs.

The environmental application of the biosynthesized ZnO NPs for the removal of $\mathrm{MO}$ and MB dyes from aqueous solution was explored and the results were presented in Figures 7 and 8. As it is presented, the first part of the experiment was carried out in the dark for 30 min to study the removal of the pollutants via the adsorption pathway, and the results revealed that the removal efficiencies due to adsorption were $52.3 \%$ and $27.2 \%$ for the $\mathrm{MO}$ and MB, respectively. Then, the photocatalytic properties of ZnO NPs on the degradation of $\mathrm{MO}$ and $\mathrm{MB}$ dyes were studied under direct sunlight for $100 \mathrm{~min}$, and it was observed that the degradation was generally in two stages. The first stage of the photodegradation was fast, followed by a slower stage. The slow degradation in the second stage might may be due to difficulty to oxidize of the $\mathrm{N}$-atoms of the dye in addition to the accumulated intermediates in the first stage decrease the rate of oxidative photocatalytic reaction [57]. 


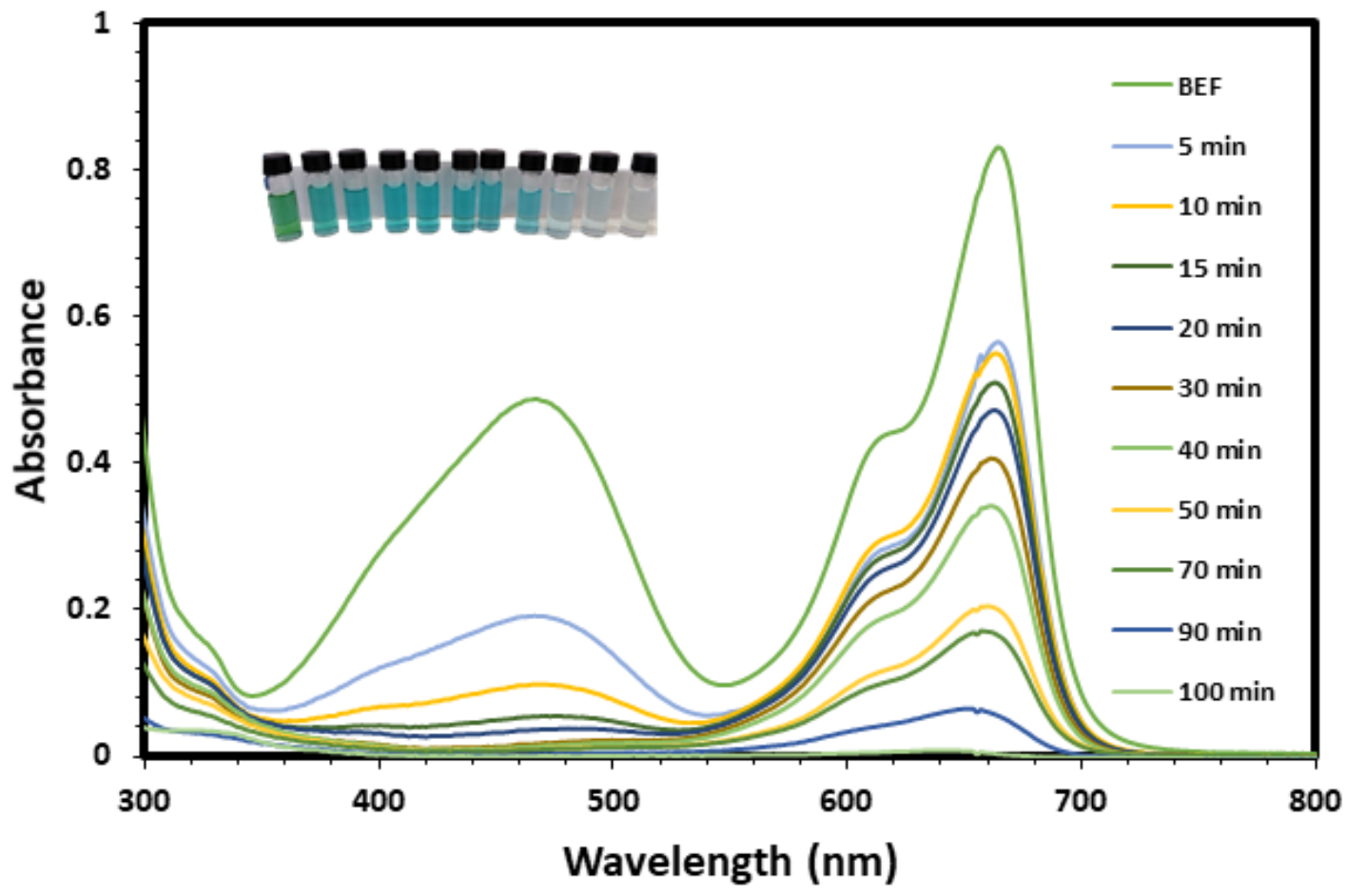

Figure 7. UV-Vis spectra of MO and MB dyes as a function of time in the presence of BMW ZnO NPs.

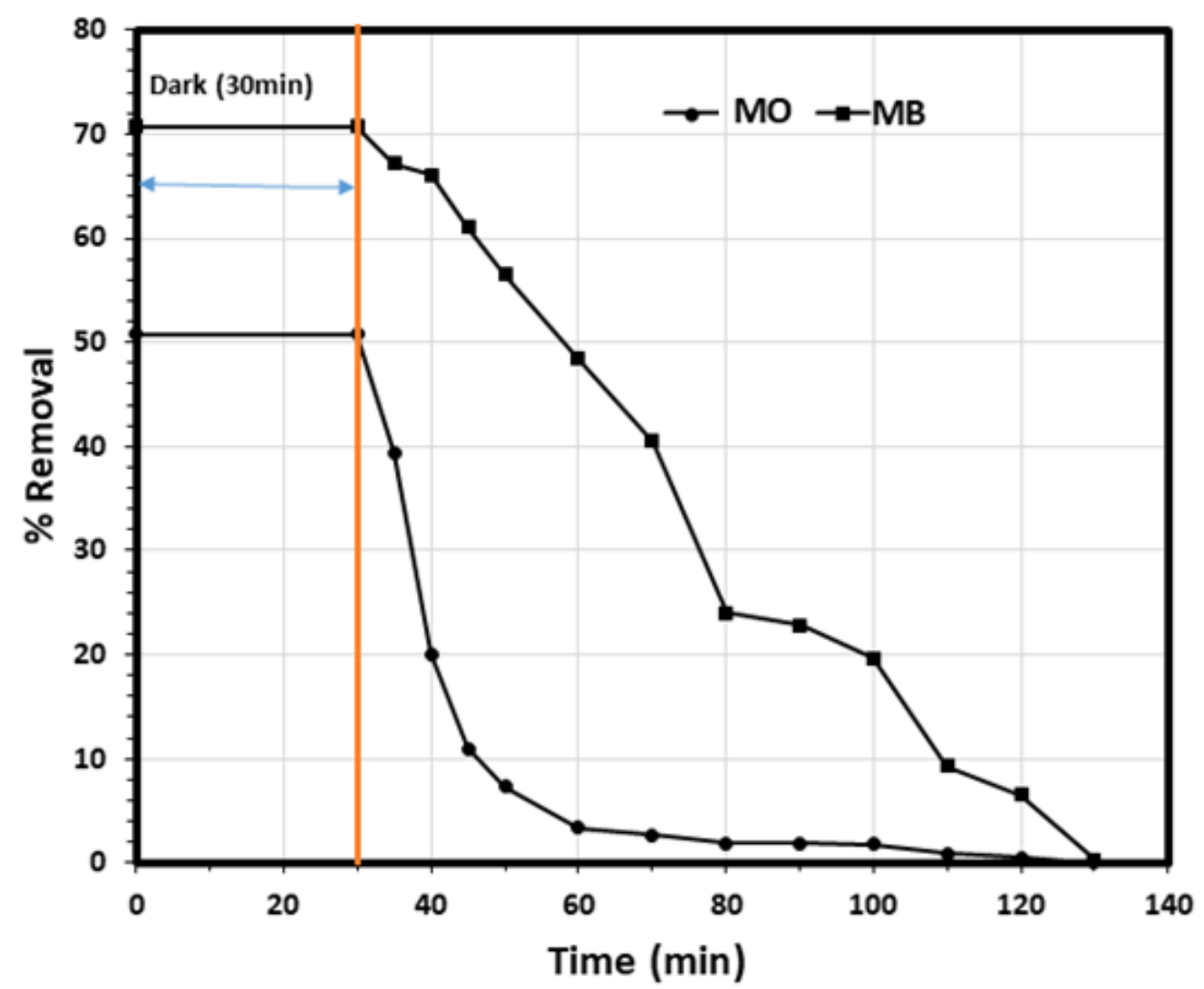

Figure 8. Removal efficiency of a model mixture solution containing MO and MB over BMW ZnO NPs. (Experimental conditions: $20.0 \mathrm{~mL}$ solution, pH 6, BMW ZnO NPs mass $15.0 \mathrm{mg}, 298 \mathrm{~K}$ and [MO] $5.0 \mathrm{mg} / \mathrm{L}$, [MB] 5.0 mg/L). 
The kinetics of MO, MB dyes photodegradation was explored, using the first order model to determine the kinetics rate in the photodegradation process of $\mathrm{MO}$ and MB dyes by the biosynthesized $\mathrm{ZnO}$ NPs according to the following equation:

$$
\ln \left(\frac{C_{t}}{C_{0}}\right)=-k t
$$

where $C_{0}, C_{t}$ and $k$ are the initial concentration, the concentration at different irradiation times $(\mathrm{mg} / \mathrm{L})$ of $\mathrm{MO}$ and $\mathrm{MB}$ dye, and the photodegradation rate constant $\left(\mathrm{min}^{-1}\right)$, respectively. As it is presented in Figure 9, the plot of $\ln \left(C_{t} / C_{0}\right)$ versus time ( $\left.\mathrm{t}\right)$ for both $\mathrm{MO}$ and $\mathrm{MB}$ dyes photodegradation experimental data showed in Figure 8, yield straight lines with slopes equal to $k$ with the linear correlation coefficient value $\left(\mathrm{R}^{2}\right)$ higher than 0.90 indicating that the photodegradation of the $\mathrm{MO}$ and $\mathrm{MB}$ dyes by the ZnO NPs follows the first order kinetics behavior, with a photodegradation rate constants of $0.0545 \mathrm{~min}^{-1}$ and $0.0241 \mathrm{~min}^{-1}$ for the $\mathrm{MO}$ and $\mathrm{MB}$, respectively, indicating the high photodegradation rate of the $\mathrm{MO}$ dye compared with the MB dye by the ZnO NPs. Intriguingly, this may indicate the significant role of the organic dye molecule charge on the removal process as $\mathrm{MO}$ is anionic dye whereas $\mathrm{MB}$ is a cationic dye. As it was observed earlier, the adsorption (in the dark) of the MO dye molecules was much more compared with the MB dye molecule-52.3\% and 27.2\%, respectively, indicating the selective nature of the ZnO NPs for the adsorption and further photocatalytic degradation of the $\mathrm{MO}$ dye compared with the MB dye.

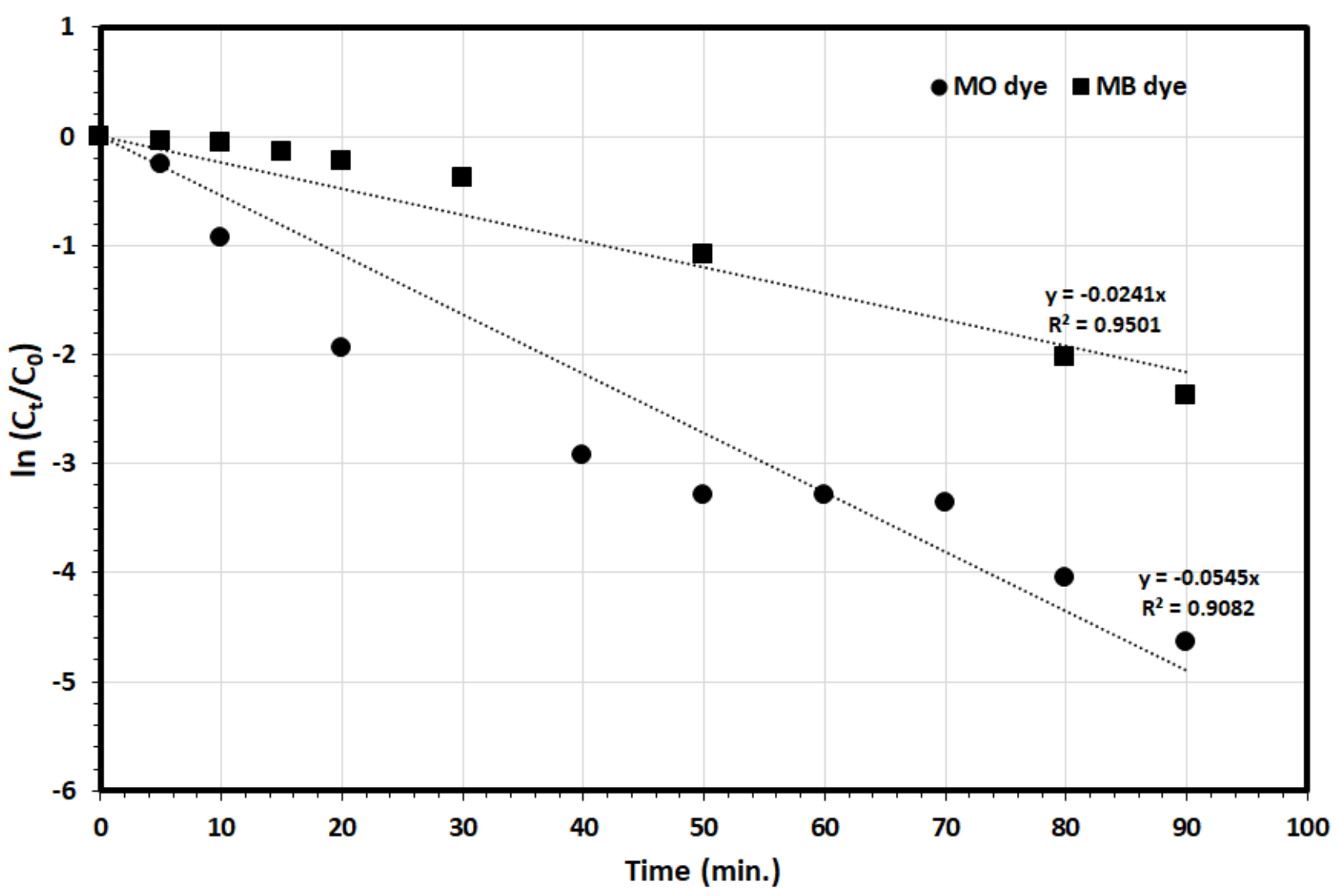

Figure 9. Kinetic plots for the photocatalytic degradation of MO and MB over BMW ZnO NPs. (Experimental conditions: $20.0 \mathrm{~mL}$ solution, pH 6, BMW ZnO NPs mass $15.0 \mathrm{mg}$, $298 \mathrm{~K}$ and [MO] $5.0 \mathrm{mg} / \mathrm{L}$, [MB] $5.0 \mathrm{mg} / \mathrm{L}$ ). 


\subsection{Photodegradation Mechanism}

The photocatalytic degradation reaction of the $\mathrm{MO}$ and $\mathrm{MB}$ dyes by $\mathrm{ZnO}$ NPs generally includes the following steps: photoexcitation, charge separation and migration and finally surface oxidation-reduction reactions [58], as it explained by Equations (5)-(11), the reactive species generated during irradiation of the $\mathrm{ZnO} \mathrm{NPs}$ were $\mathrm{h}_{(\mathrm{VB})}^{+}, \mathrm{OH} \cdot$ and $\mathrm{O}_{2}^{-}$.

$$
\begin{gathered}
\mathrm{ZnO} \rightarrow \mathrm{ZnO}\left(\mathrm{e}_{(\mathrm{CB})}^{-}\right)+\left(\mathrm{h}_{(\mathrm{VB})}^{+}\right) \\
\mathrm{ZnO}\left(\mathrm{h}_{(\mathrm{VB})}^{+}\right)+\mathrm{H}_{2} \mathrm{O} \rightarrow \mathrm{ZnO}+\mathrm{H}^{+}+\mathrm{OH} \\
\mathrm{ZnO}\left(\mathrm{e}_{(\mathrm{CB})}^{-}\right)+\mathrm{O}_{2} \rightarrow \mathrm{ZnO}+\mathrm{O}_{2}^{-.} \\
\mathrm{O}_{2}^{-}+\mathrm{H}^{+} \rightarrow \mathrm{HO}_{2} \\
\mathrm{HO}_{2}+\mathrm{HO}_{2} \rightarrow \mathrm{H}_{2} \mathrm{O}_{2}+\mathrm{O}_{2} \\
\mathrm{H}_{2} \mathrm{O}_{2} \stackrel{h v}{\rightarrow} 2 \mathrm{OH} \\
\text { Organic pollutants }+\mathrm{OH}^{-} \rightarrow \text { degradation products }
\end{gathered}
$$

Figure 10 presents the proposed mechanism for photocatalytic degradation of MO and MB dyes by ZnO NPs photocatalyst under solar irradiation. It is proposed that the electrons in the $\mathrm{VB}$ transfer to the $\mathrm{CB}$ under the solar irradiation of the of the $\mathrm{ZnO} \mathrm{NPs}$, and the corresponding energy is higher than the band gap of $\mathrm{ZnO}(2.7 \mathrm{eV})$, in that way promoting the generation of valance band holes $\left(\mathrm{h}^{+}\right)$and conduction band electrons $\left(\mathrm{e}^{-}\right)$, and possibly, the photogenerated holes at the VB could either directly oxidize the adsorbed $\mathrm{MO}$ and $\mathrm{MB}$ dyes or directly react with hydroxyl $\left(\mathrm{OH}^{-}\right)$or $\mathrm{H}_{2} \mathrm{O}$ to generate hydroxyl radicals $(\cdot \mathrm{OH})$. Meanwhile, the photoelectrons at the $\mathrm{CB}$ could reduce the oxygen $\left(\mathrm{O}_{2}\right)$ adsorbed on the $\mathrm{ZnO}$ NPs surface into superoxide radical $\left(\cdot \mathrm{O}_{2}{ }^{-}\right)$. Accordingly, the $\mathrm{MO}$ and $\mathrm{MB}$ dyes could be decomposed photocatalytically by the both generated $\cdot \mathrm{OH}$ and $\cdot \mathrm{O}_{2}{ }^{-}[59-61]$.

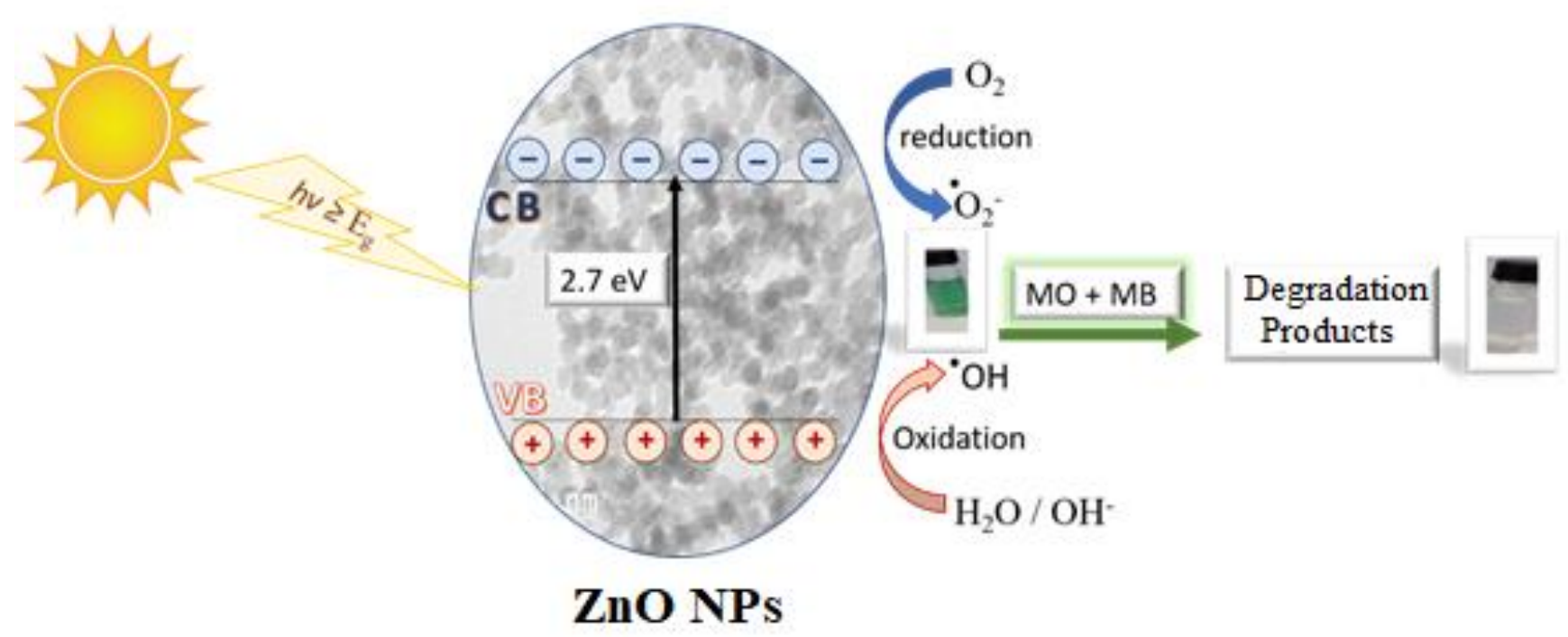

Figure 10. The proposed mechanism for the photo-degradation of MO,MB dyes by the BMW ZnO NPs.

\section{Conclusions}

Zinc oxide nanoparticles were biosynthesized using Ziziphus jujuba leaves extract assisted with microwave and used for the photocatalytic degradation of the methyl orange anionic dye and the methylene blue cationic dye under solar irradiation. The biosyn- 
thesized ZnO NPs were characterized and the results showed that ZnO NPs contained hexagonal wurtzite and was characterized with a well-defined spherical-like shape with an average particle size of $25 \mathrm{~nm}$ with an outstanding band gap of $2.7 \mathrm{eV}$ and surface area of $11.4 \mathrm{~m}^{2} / \mathrm{g}$. The photocatalytic degradation of the MO and MB dyes by biosynthesized $\mathrm{ZnO}$ NPs under solar irradiation was studied and the results revealed the selective nature of the $\mathrm{ZnO}$ NPs for the adsorption and further photocatalytic degradation of the MO dye compared with the MB dye. In addition, the photocatalytic degradation of $\mathrm{MO}$ and $\mathrm{MB}$ dyes by the ZnO NPs under solar radiation was fitted by the first-order kinetics. Moreover, the photodegradation mechanism proposed that superoxide ions and hydroxyl radicals are the main reactive species.

Author Contributions: Conceptualization, S.B., and M.A.S.; methodology, M.N.A., I.I., and M.A.S.; software, N.H.K.; validation, S.B., and I.I.; formal analysis, M.N.A., and M.A.S.; investigation, M.N.A., and M.A.S.; resources, M.A.S.; data curation, M.N.A.; writing-original draft preparation, M.N.A.; writing-review and editing, M.N.A. and M.A.S.; visualization, S.B.; supervision, M.A.S. and I.I.; project administration, I.I.; funding acquisition, M.A.S. All authors have read and agreed to the published version of the manuscript.

Funding: This project was funded by the Deanship of Scientific Research (DSR), King Abdulaziz University, Jeddah, Saudi Arabia under grant no. (KEP-PhD-2-130-40). The authors, therefore, acknowledge with thanks DSR technical and financial support.

Data Availability Statement: Not applicable.

Acknowledgments: This project was funded by the Deanship of Scientific Research (DSR), King Abdulaziz University, Jeddah, Saudi Arabia under grant no. (KEP-PhD-2-130-40). The authors, therefore, acknowledge with thanks DSR technical and financial support.

Conflicts of Interest: The authors declare no conflict of interest.

\section{References}

1. Al-Dahiri, R.H.; Turkustani, A.M.; Salam, M.A. The application of zinc oxide nanoparticles as an eco-friendly inhibitor for steel in acidic solution. Int. J. Electrochem. Sci. 2020, 15, 442-457. [CrossRef]

2. Espitia, P.J.P.; Soares, N.D.F.F.; Coimbra, J.S.D.R.; De Andrade, N.J.; Cruz, R.S.; Medeiros, E.A.A. Zinc Oxide Nanoparticles: Synthesis, Antimicrobial Activity and Food Packaging Applications. Food Bioprocess. Technol. 2012, 5, 1447-1464. [CrossRef]

3. Prasad, A.R.; Williams, L.; Garvasis, J.; Shamsheera, K.; Basheer, S.M.; Kuruvilla, M.; Joseph, A. Applications of phytogenic ZnO nanoparticles: A review on recent advancements. J. Mol. Liq. 2021, 331, 115805. [CrossRef]

4. Cauda, V.; Laurenti, M. Editorial for Special Issue: ZnO Nanostructures for Tissue Regeneration, Drug-Delivery and Theranostics Applications. Nanomaterials 2021, 11, 296. [CrossRef] [PubMed]

5. Sana, S.S.; Li, H.; Zhang, Z.; Sharma, M.; Usmani, Z.; Hou, T.; Netala, V.R.; Wang, X.; Gupta, V.K. Recent advances in es-sential oils-based metal nanoparticles: A review on recent developments and biopharmaceutical applications. J. Mol. Liq. 2021, 333, 115951. [CrossRef]

6. Subramanian, V.; Bakhishev, T.; R, D.; Volkman, S.K. Solution-Processed Zinc Oxide Transistors for Low-Cost Electronics Ap-plications. J. Disp. Technol. 2009, 5, 525-530. [CrossRef]

7. Sabir, S.; Arshad, M.; Chaudhari, S.K. Zinc Oxide Nanoparticles for Revolutionizing Agriculture: Synthesis and Applications. Sci. World J. 2014, 2014, 1-8. [CrossRef]

8. Becheri, A.; Dürr, M.; Nostro, P.L.; Baglioni, P. Synthesis and characterization of zinc oxide nanoparticles: Application to textiles as UV-absorbers. J. Nanoparticle Res. 2008, 10, 679-689. [CrossRef]

9. Lee, K.M.; Lai, C.W.; Ngai, K.S.; Juan, J.C. Recent developments of zinc oxide based photocatalyst in water treatment tech-nology: A review. Water Res. 2016, 88, 428-448. [CrossRef]

10. Mirzaei, A.; Chen, Z.; Haghighat, F.; Yerushalmi, L. Removal of pharmaceuticals and endocrine disrupting compounds from water by zinc oxide-based photocatalytic degradation: A review. Sustain. Cities Soc. 2016, 27, 407-418. [CrossRef]

11. Bae, K.-L.; Kim, J.; Lim, C.K.; Nam, K.M.; Song, H. Colloidal zinc oxide-copper(I) oxide nanocatalysts for selective aqueous photocatalytic carbon dioxide conversion into methane. Nat. Commun. 2017, 8, 1156. [CrossRef] [PubMed]

12. Ong, C.B.; Ng, L.Y.; Mohammad, A.W. A review of ZnO nanoparticles as solar photocatalysts: Synthesis, mecha-nisms and applications. Renew. Sustain. Energy Rev. 2018, 81, 536-551. [CrossRef]

13. Xin, C.; Hu, M.; Wang, K.; Wang, X. Significant Enhancement of Photocatalytic Reduction of CO2 with $\mathrm{H} 2 \mathrm{O}$ over ZnO by the Formation of Basic Zinc Carbonate. Langmuir 2017, 33, 6667-6676. [CrossRef] [PubMed]

14. Singh, T.A.; Das, J.; Sil, P.C. Historical Perspective Zinc oxide nanoparticles: A comprehensive review on its synthesis, anticancer and drug delivery applications as well as health risks. Adv. Colloid Interface Sci. 2020, 286, 102317. [CrossRef] [PubMed] 
15. Ali, A.; Phull, A.R.; Zia, M. Elemental zinc to zinc nanoparticles: Is ZnO NPs crucial for life? Synthesis, toxicological, and environmental concerns. Nanotechnol. Rev. 2018, 7, 413-441. [CrossRef]

16. Akhil, K.; Jayakumar, J.; Gayathri, G.; Khan, S.S. Effect of various capping agents on photocatalytic, antibacterial and anti-biofilm activities of $\mathrm{ZnO}$ nanoparticles. J. Photochem. Photobiol. B Biol. 2016, 160, 32-42. [CrossRef]

17. Basnet, P.; Chanu, T.I.; Samanta, D.; Chatterjee, S. A review on bio-synthesized zinc oxide nanoparticles using plant ex-tracts as reductants and stabilizing agents. J. Photochem. Photobiol. B Biol. 2018, 183, 201-221. [CrossRef] [PubMed]

18. Bhuyan, T.; Mishra, K.; Khanuja, M.; Prasad, R.; Varma, A. Biosynthesis of zinc oxide nanoparticles from Azadirachta indi-ca for antibacterial and photocatalytic applications. Mater. Sci. Semicond. Process. 2015, 32, 55-61. [CrossRef]

19. Prasad, A.R.; Garvasis, J.; Oruvil, S.K.; Joseph, A. Bio-inspired green synthesis of zinc oxide nanoparticles using Abel-moschus esculentus mucilage and selective degradation of cationic dye pollutants. J. Phys. Chem. Solids 2019, 127, 265-274. [CrossRef]

20. Zare, E.; Pourseyedi, S.; Khatami, M.; Darezereshki, E. Simple biosynthesis of zinc oxide nanoparticles using nature's source, and it's in vitro bio-activity. J. Mol. Struct. 2017, 1146, 96-103. [CrossRef]

21. Rajeshkumar, S.; Kumar, S.V.; Ramaiah, A.; Agarwal, H.; Roopan, T.L.S.M. Enzyme and Microbial Technology Biosyn-thesis of zinc oxide nanoparticles using Mangifera indica leaves and evaluation of their antioxidant and cytotoxic proper-ties in lung cancer (A549) cells. Enzyme Microb. Technol. 2018, 117, 91-95. [CrossRef] [PubMed]

22. Chaudhuri, S.K.; Malodia, L. Biosynthesis of zinc oxide nanoparticles using leaf extract of Calotropis gigantea: Characteri-zation and its evaluation on tree seedling growth in nursery stage. Appl. Nanosci. 2017, 7, 501-512. [CrossRef]

23. Fahimmunisha, B.A.; Ishwarya, R.; AlSalhi, M.S.; Devanesan, S.; Govindarajan, M.; Vaseeharan, B. Green fabrication, characterization and antibacterial potential of zinc oxide nanoparticles using Aloe socotrina leaf extract: A novel drug delivery approach. J. Drug Deliv. Sci. Technol. 2020, 55, 101465. [CrossRef]

24. Paul, B.; Vadivel, S.; Dhar, S.S.; Debbarma, S.; Kumaravel, M. One-pot green synthesis of zinc oxide nano rice and its ap-plication as sonocatalyst for degradation of organic dye and synthesis of 2-benzimidazole derivatives. J. Phys. Chem. Solids 2017, 104, 152-159. [CrossRef]

25. Al-Shabib, N.A.; Husain, F.M.; Ahmed, F.; Khan, R.A.; Ahmad, I.; Alsharaeh, E.; Khan, M.S.; Hussain, A.; Rehman, T.; Yusuf, M.; et al. Biogenic synthesis of Zinc oxide nanostructures from Nigella sativa seed: Prospective role as food packaging material inhibiting broad-spectrum quorum sensing and biofilm. Sci. Rep. 2016, 6, 36761. [CrossRef]

26. Golmohammadi, M.; Honarmand, M.; Ghanbari, S. A green approach to synthesis of ZnO nanoparticles using jujube fruit extract and their application in photocatalytic degradation of organic dyes. Spectrochim. Acta Part. A Mol. Biomol. Spectrosc. 2020, 229, 117961. [CrossRef]

27. Ahmed, S.; Chaudhry, S.A.; Ikram, S. A review on biogenic synthesis of ZnO nanoparticles using plant extracts and microbes: A prospect towards green chemistry. J. Photochem. Photobiol. B: Biol. 2017, 166, 272-284. [CrossRef]

28. Wang, M.; Gao, Q.; Shen, J.; Wang, X.; Ji, X. The Jujube (Ziziphus jujuba Mill.) Fruit: A Review of Current Knowledge of Fruit Composition and Health Benefits. In Chinese Dates, 1st ed.; CRC Press: Boca Raton, FL, USA, 2016; 30p.

29. El-Seedi, H.R.; Khalifa, S.A.M.; Yosri, N.; Khatib, A.; Chen, L.; Saeed, A.; Efferth, T.; Verpoorte, R. Review Plants mentioned in the Islamic Scriptures (Holy Qur'ân and Ahadith): Traditional uses and medicinal importance in contemporary times. J. Ethnopharmacol. 2019, 243, 112007. [CrossRef]

30. Farooqi, M.I.H. Plants of the Qur'an; Sidrah Publishers: Lucknow, India, 1997.

31. Abedini, Z.T.M.R.; Mitra, M.; Fard, M.H.; Beydokhti, H. “Ziziphus jujuba”: A red fruit with promising anti-cancer activities. Pharmacogn. Rev. 2015, 9, 99-106.

32. Halawani, E.M. Rapid Biosynthesis Method and Characterization of Silver Nanoparticles Using Zizyphus spina christi Leaf Extract and Their Antibacterial Efficacy in Therapeutic Application. J. Biomater. Nanobiotechnol. 2017, 8, 22-35. [CrossRef]

33. Aljabali, A.A.A.; Akkam, Y.; Al Zoubi, M.S.; Al-Batayneh, K.M.; Al-Trad, B.; Alrob, O.A.; Alkilany, A.M.; Benamara, M.; Evans, D.J. Synthesis of Gold Nanoparticles Using Leaf Extract of Ziziphus zizyphus and their Antimicrobial Activity. Nanomaterials 2018, 8, 174. [CrossRef] [PubMed]

34. Wojnarowicz, J.; Chudoba, T.; Lojkowski, W. A Review of Microwave Synthesis of Zinc Oxide Nanomaterials: Reactants, Process Parameters and Morphologies. Nanomaterials 2020, 10, 1086. [CrossRef] [PubMed]

35. Mirzaei, A.; Neri, G. Microwave-assisted synthesis of metal oxide nanostructures for gas sensing application: A review. Sens. Actuators B Chem. 2016, 237, 749-775. [CrossRef]

36. Kumar, A.; Kuang, Y.; Liang, Z.; Sun, X. Microwave chemistry, recent advancements, and eco-friendly microwave-assisted synthesis of nanoarchitectures and their applications: A review. Mater. Today Nano 2020, 11, 100076. [CrossRef]

37. Garino, N.; Limongi, T.; Dumontel, B.; Canta, M.; Racca, L.; Laurenti, M.; Castellino, M.; Casu, A.; Falqui, A.; Cauda, V. A mi-crowave-assisted synthesis of zinc oxide nanocrystals finely tuned for biological applications. Nanomaterials $2019,9,212$. [CrossRef]

38. Salah, N.; Al-Shawafi, W.M.; Alshahrie, A.; Baghdadi, N.; Soliman, Y.M.; Memic, A. Size controlled, antimicrobial ZnO nanostructures produced by the microwave assisted route. Mater. Sci. Eng. C 2019, 99, 1164-1173. [CrossRef] [PubMed]

39. Papadaki, D.; Foteinis, S.; Mhlongo, G.H.; Nkosi, S.S.; Motaung, D.E.; Ray, S.S.; Tsoutsos, T.; Kiriakidis, G. Life cycle assess-ment of facile microwave-assisted zinc oxide (ZnO) nanostructures. Sci. Total Environ. 2017, 586, 566-575. [CrossRef]

40. Klug, H.P.; Alexander, L.E. X-Ray Diffraction Procedures, 2nd ed.; Wiley: Hoboken, NJ, USA, 1974; Chapter 9. 
41. Ji, X.; Zhang, F.; Zhang, R.; Liu, F.; Peng, Q.; Wang, M. An acidic polysaccharide from Ziziphus Jujuba cv. Muzao: Purification and structural characterization. Food Chem. 2019, 274, 494-499. [CrossRef]

42. Yuan, C.; Huo, C.; Gui, B.; Liu, J.; Chen, Y. Facile phyto-mediated synthesis of silver nanoparticles using Chinese winter jujube (Ziziphus jujuba Mill. cv. Dongzao) extract and their antibacterial/catalytic properties. IET Nanobiotechnol. 2017, 11, 973-980. [CrossRef]

43. Sangeetha, G.; Rajeshwari, S.; Venckatesh, R. Green synthesis of zinc oxide nanoparticles by aloe barbadensis miller leaf extract: Structure and optical properties. Mater. Res. Bull. 2011, 46, 2560-2566. [CrossRef]

44. West, A. Solid State Chemistry and Its Applications; Wiley: New York, NY, USA, 1986.

45. Damiano, S.; Forino, M.; De, A.; Vitali, L.A.; Lupidi, G.; Taglialatela-Scafati, O. Antioxidant and antibiofilm activities of secondary metabolites from Ziziphus jujuba leaves used for infusion preparation. Food Chem. 2017, 230, 24-29. [CrossRef] [PubMed]

46. Gavade, N.L.; Kadam, A.N.; Suwarnkar, M.B.; Ghodake, V.P.; Garadkar, K.M. Biogenic synthesis of multi-applicative silver nanoparticles by using Ziziphus Jujuba leaf extract. Spectrochim. Acta Part A Mol. Biomol. Spectrosc. 2015, 136, 953-960. [CrossRef]

47. Wang, B.; Huang, Q.; Venkitasamy, C.; Chai, H.; Gao, H.; Cheng, N.; Cao, W.; Lv., X.; Pan, Z. Changes in phenolic compounds and their antioxidant capacities in jujube (Ziziphus jujuba Miller) during three edible maturity stages. LWT Food Sci. Technol. 2016, 66, 56-62. [CrossRef]

48. Guimarães, M.L.; da Silva, F.A.G.; da Costa, M.M.; de Oliveira, H.P. Green synthesis of silver nanoparticles using Ziziphus joazeiro leaf extract for production of antibacterial agents. Appl. Nanosci. 2020, 10, 1073-1081. [CrossRef]

49. Wojnarowicz, J.; Opalinska, A.; Chudoba, T.; Gierlotka, S.; Mukhovskyi, R.; Pietrzykowska, E.; Sobczak, K.; Lojkowski, W. Effect of Water Content in Ethylene Glycol Solvent on the Size of ZnO Nanoparticles Prepared Using Microwave Sol-vothermal Synthesis. J. Nanomater. 2016, 15. [CrossRef]

50. Wejrzanowski, T.; Pielaszek, R.; Opalińska, A.; Matysiak, H.; Łojkowski, W.; Kurzydłowski, K. Quantitative methods for nanopowders characterization. Appl. Surf. Sci. 2006, 253, 204-208. [CrossRef]

51. Tauc, J. (Ed.) Amorphous and Liquid Semiconductor; Plenum Press: New York, NY, USA, 1974.

52. Gupta, A.; Saurav, J.R.; Bhattacharya, S. Solar light based degradation of organic pollutants using ZnO nanobrushes for water filtration. RSC Adv. 2015, 5, 71472-71481. [CrossRef]

53. Galdámez-Martinez, A.; Santana, G.; Güell, F.; Martínez-Alanis, P.R.; Dutt, A. Photoluminescence of ZnO Nanowires: A Review. Nanomaterials 2020, 10, 857. [CrossRef]

54. Sheetz, R.M.; Ponomareva, I.; Richter, E.; Andriotis, A.N.; Menon, M. Defect-induced optical absorption in the visible range in ZnO nanowires. Phys. Rev. B 2009, 80, 195314. [CrossRef]

55. Ahmed, G.; Hanif, M.; Zhao, L.; Hussain, M.; Khan, J.; Liu, Z. Defect engineering of ZnO nanoparticles by graphene oxide leading to enhanced visible light photocatalysis. J. Mol. Catal. A Chem. 2016, 425, 310-321. [CrossRef]

56. Balázs, N.; Mogyorósi, K.; Srankó, D.F.; Pallagi, A.; Alapi, T.; Oszkó, A.; Dombi, A.; Sipos, P. The effect of particle shape on the activity of nanocrystalline TiO2 photocatalysts in phenol decomposition. Appl. Catal. B Environ. 2008, 84, 356-362. [CrossRef]

57. Blaskov, V.N.; Stambolova, I.D.; Milenova, K.I.; Zahariev, K.L.; Dimitrov, L.D.; Stoyanova, D.D.; Eliyas, A.E. The pho-todegradation of Methylene Blue and Methyl Orange dyes and their mixture by $\mathrm{ZnO}$ obtained by hydrothermally activated precipitates. Bulg. Chem. Commun. 2017, 49, 183-187.

58. Li, H.H.; Yin, S.; Wang, Y.H.; Sato, T. Efficient persistent photocatalytic decomposition of nitrogen monoxide over a fluo-rescenceassisted CaAl2O4: (Eu, Nd)/(Ta, N)-codoped TiO2/Fe2O3. Appl. Catal. B Environ. 2013, 132, 487-492. [CrossRef]

59. Palanisamy, B.; Babu, C.M.; Sundaravel, B.; Anandan, S.; Murugesan, V. Sol-gel synthesis of mesoporous mixed Fe2O3/TiO2 photocatalyst: Application for degradation of 4-chlorophenol. J. Hazard. Mater. 2013, 252, 233-242. [CrossRef]

60. Chen, X.; Wu, Z.; Liu, D.; Gao, Z. Preparation of ZnO Photocatalyst for the Efficient and Rapid Photocatalytic Degradation of Azo Dyes. Nanoscale Res. Lett. 2017, 12, 1-10. [CrossRef] [PubMed]

61. Zhanyi, L.; Guoguang, L.; Qing, S.; Chunyan, L.; Xiaoyu, J.; Xiaoqing, W. UV-Induced Photodegradation of Naproxen Using a Nano $\gamma$-FeOOH Composite: Degradation Kinetics and Photocatalytic Mechanism. Front. Chem. 2019, 7, 847. 